\title{
Isolation and characterization of chitin from Millipede (Spirobolida)
}

\author{
Raghu H. S, Raghavendra S. N and Rajeshwara N. Achur
}

\begin{abstract}
Background: Chitin is the second most abundant bio-polysaccharide found in nature after cellulose. It is a polymer of $\beta-1,4-N$-acetylglucosamine that occurs naturally in three polymorphic forms $a, \beta$, and $y$-chitin. The main commercial sources of chitin are crab and shrimp shells which are the major waste products from the seafood industry. The main aim of the current work was to isolate chitin from a local variety of Millipede (Spirobolida), which is abundantly found in Western Ghat region of Karnataka during monsoon and post-monsoon seasons.

Methods: The millipedes were collected during the monsoon season from Western Ghat region and washed with distilled water. The shells were extracted from Millipede by incinerating the sample to remove other organic matter. The chitin was extraction from the shell by demineralization and deproteinization.

Results: Chitin was extracted and analyzed by Fourier transform infrared (FT-IR) spectroscopy and scanning electron microscopy (SEM) studies. The yield of chitin was found to be $35.7 \%$. This is a good yield percentage compared to that of the chitin obtained from conventional sources.

Conclusions: The chitin thus obtained can be employed for preparing chitosan linked nanoparticles for various applications. Hence, our studies illustrate that Millipedes can also be used as a source for large-scale extraction of chitin.
\end{abstract}

Keywords: Chitin, Millipede, Spirobolida, Scanning electron microscopy, Fourier transform infrared (FT-IR) spectroscopy

\section{Background}

Chitin is a polysaccharide widely distributed in marine invertebrates, crustacean shells, insect's cuticles, fungus cell walls, and yeast (Austin, Castle, \& Albisetti, 1989). It is the second most abundant biopolymer after cellulose (No \& Meyers, 1989). The shells of selected crustaceans consist of $30-40 \%$ protein, $30-50 \%$ calcium carbonate and calcium phosphate, and $20-30 \%$ of chitin (Knorr, 1984). Chitin is commonly isolated from the exoskeletons of crustaceans and more particularly from shrimps and crabs (Austin et al., 1989; Minke \& Blackwell, 1978).

Structurally, chitin consists of 2-acet-amido 2-deoxy-b-D-glucose through a $\beta$ (Austin et al., 1989; Gardner \& Blakwell, 1975) linkage. Chitin is structurally and functionally similar to cellulose. Naturally, chitin exists in three different forms $\alpha, \beta$, and $\gamma$ with different chitin microfibril orientations (Rudall, 1963). The $\alpha$-form is made up of antiparallel chains, and it is the

\footnotetext{
* Correspondence: hsr1983@gmail.com Department of Biochemistry, Kuvempu University, Shankarghatta, Shivamogga, Karnataka 577451, India
}

most abundant form. It is present in shells of crustaceans, skeletons of members of family Mollusca, and insect's cuticles. It is also found in cell walls of fungi (Gardner \& Blakwell, 1975; Kameda, Miyazawa, Ono, \& Yoshida, 2005). The $\beta$-form is made up of parallel chains, and it is a rare form of chitin. It is found in squid pins, in extracellular spines of the euryhaline diatom (Herth and Barthlott, 1979), and in pogonophore tubes (Blackwell, 1969). The $\gamma$-form is made up of both parallel and antiparallel chains. It is found in the cocoons of insects (Rudall \& Kenchington, 1973). In nature, chitin exists rarely in pure form always found in matrix associated with proteins (Knorr, 1982).

Chitin, chitosan, and their derivatives have innumerable applications in various industries (Ravi Kumar, 2000; Sandford, 1989). The applications include cosmetics, food, agriculture, biomedical, and textile as chelating agents and refinement of industrial effluents (Chassarya, Vincenta, Marcanob, Macaskiec, \& Guibala, 2005; Rathke \& Hodson, 1994). Chitin is not soluble in usual solvents, but its derivative chitosan is soluble in 
aqueous acidic solutions (Tolaimate, Desbriers, Rhazi, \& Alagui, 2003).

In the present study, we have described the isolation and characterization of chitin from Millipede (spirobolida) belongs to the group of Arthropods (Fig. 1) which can be a nonconventional source of chitin in future.

\section{Methods}

\section{Extraction of chitin}

The local variety of Millipede (Spirobolida) was collected during the early monsoon season from the Western Ghat region in the Kuvempu university campus, Shankaraghatta, Shimoga, Karnataka. The Millipedes were washed and desiccated at room temperature. The Millipede shell was extracted by incinerating the sample to remove other organic matter. The extraction of chitin from the shell includes mainly two steps that comprise of demineralization and deproteinization.

Demineralization was carried out at room temperature using concentrated hydrochloric acid $(\mathrm{HCl})$; this precipitates the calcium chloride salt. The incinerated shells were powdered, and $1 \mathrm{~g}$ of this powder was treated with $15 \mathrm{ml}$ of concentrated $\mathrm{HCl}$ and then treated with $1 \mathrm{M}$ sodium hydroxide solution in the ratio of $1: 5(w / v)$ for $24 \mathrm{~h}$ at $75{ }^{\circ} \mathrm{C}$ to remove proteins. The sample was filtered and washed with deionized water and dried.

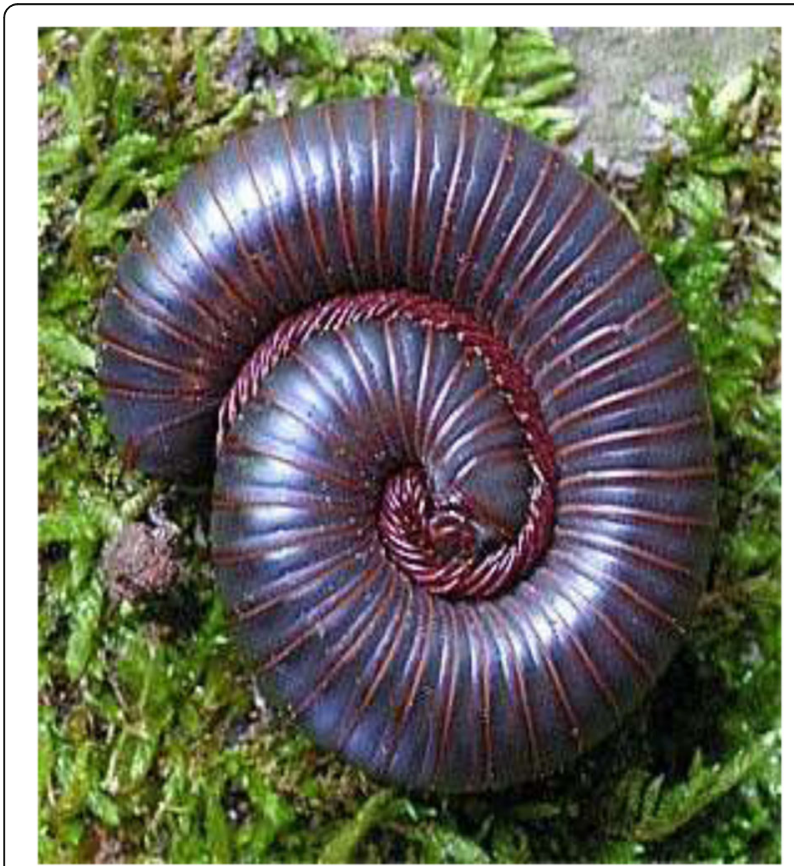

Fig. 1 Millipede (Spirobolida)

\section{FT-IR measurements}

The extracted chitin was subjected to FT-IR analysis. The measurements were carried out by employing Potassium Bromide pellet method (Brugnerottoa et al., 2001). The absorbance values were determined between 4000 and $400 \mathrm{~cm}^{-1}$ with a resolution of $4 \mathrm{~cm}^{-1}$.

\section{Scanning electron microscopy analysis}

The scanning electron microscopy (ZEISS company) analysis was performed at Mangalore University, Mangalore, Karnataka, India. The analysis was carried out with a resolution of $90,000 \times$, and it is used to examine the microstructure of extracted chitin.

\section{Results and discussion \\ Extraction of chitin}

The millipede chitin was purified by acid and alkali treatment by removing calcium chloride salt and proteins. The average yield of chitin from conventional sources is about $30-40 \%$. The yield obtained in this process was $35.7 \%$ which is as good as the yield from other conventional sources such as crab and shrimp (Abdou, Nag, \& Elsabee, 2008).

\section{FT-IR spectroscopic analysis}

The FT-IR spectrum (Fig. 2) of millipede chitin was found to be a typical one without any impurities. The absorption peaks at $1540 \mathrm{~cm}^{-1}$ assigned to the stretching vibration of proteins were absent. This confirms that the prepared Millipede chitin was protein free. In the spectrum, we can observe the characteristic $\mathrm{C}-\mathrm{O}$ stretch, Amide I, Amide II, $-\mathrm{CH}, \mathrm{CH} 3,-\mathrm{NH}$ and $-\mathrm{OH}$ groups. Further, the spectrum was comparable to the spectra of the chitin from other sources such as shrimp (Trang \& Huynh, 2015).This confirms that the isolated molecule is chitin.

\section{SEM image analysis}

The SEM analysis reveals that the chitin isolated from millipede showed a clear aggregation which appears like nanoparticles. This can be due to their intrasheet and intersheet hydrogen bonds (Fig. 3). It has been reported earlier that these chitin form micro-aggregate forming nanoparticular and nanofibrous structures.

\section{Conclusions}

The conventional sources for isolation of chitin are crab, shrimp, and krill shells that constitute wastes from the processing of marine food products. In recent years, there has been a search for nonconventional sources of chitin apart from these traditional sources. As a result of this, now many insects and fungal mycelia are also being explored. In our study, we have isolated chitin from Millipede which can be an alternative nonconventional 


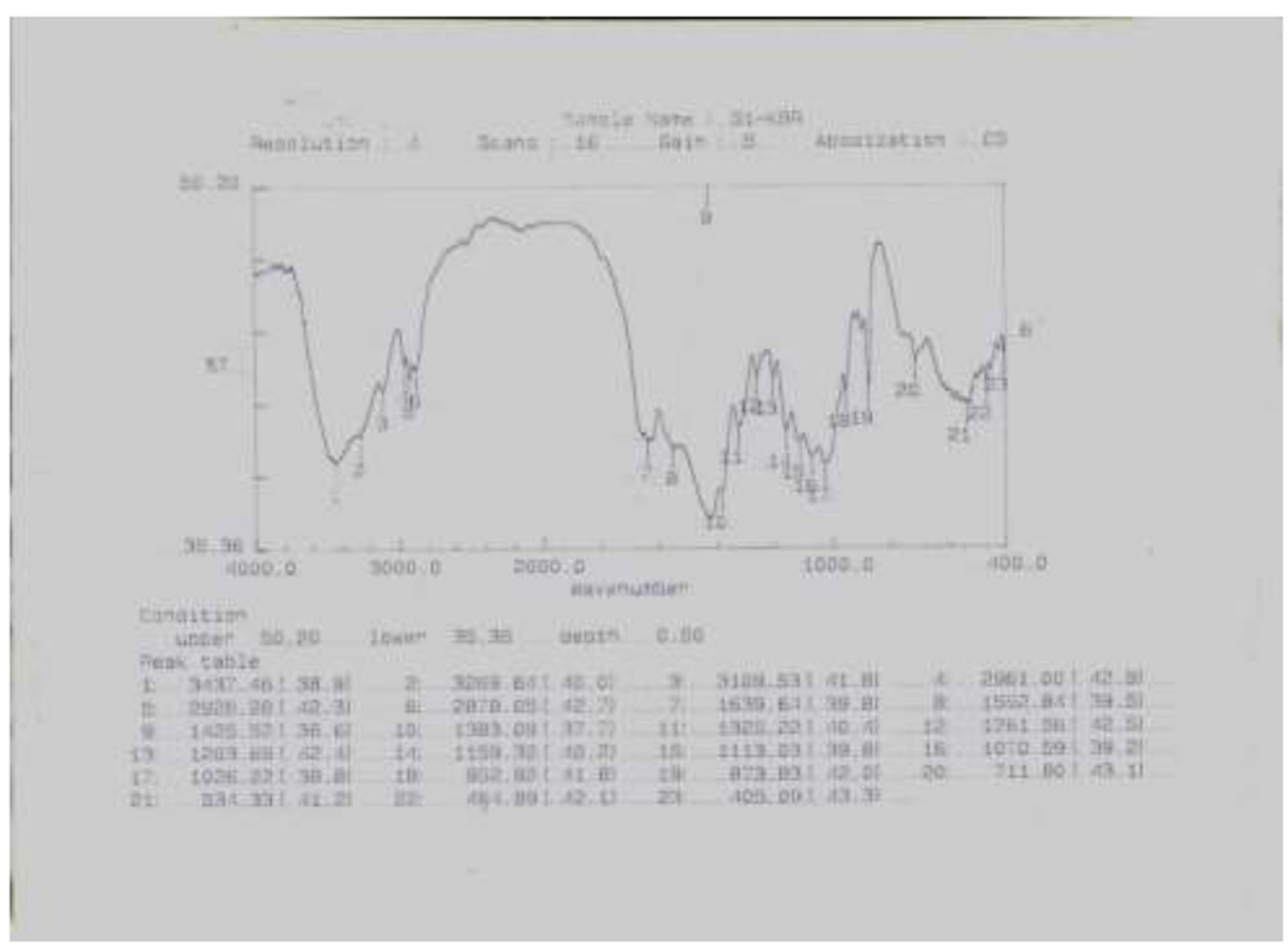

Fig. 2 FT-IR spectra of chitin extracted from Millipede

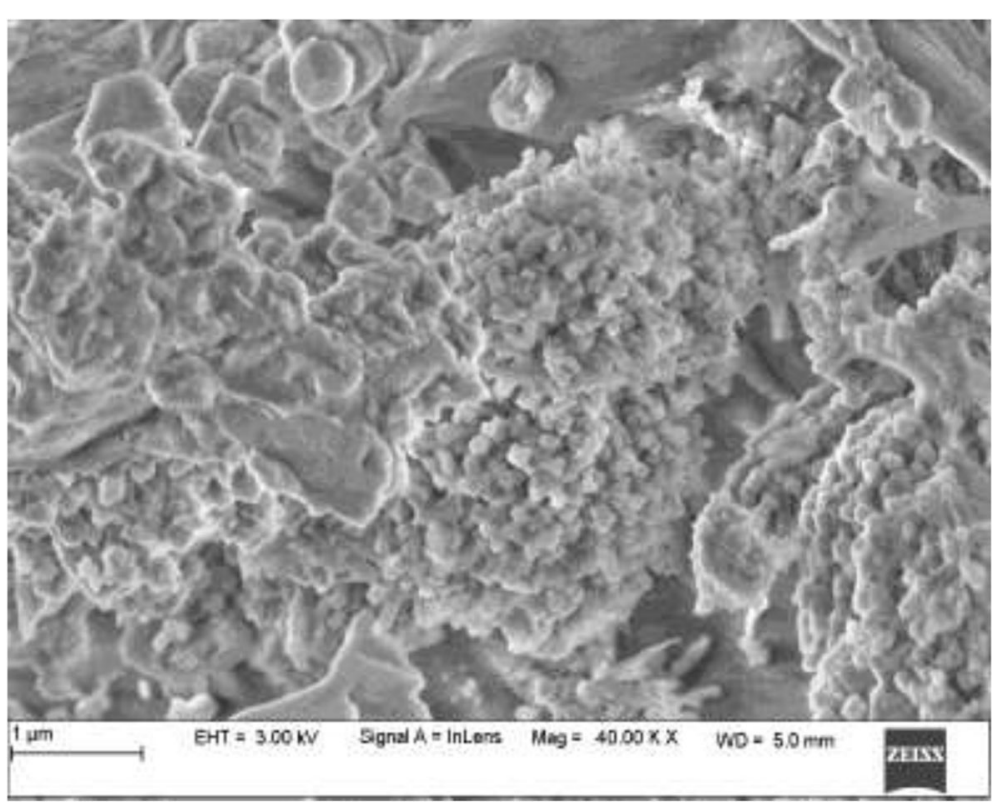

Fig. 3 SEM images of chitin from Millipede 
source for chitin. It was observed that in the Western Ghat region in Karnataka, India, lot of millipedes killed due to human activities during the rainy season, so these millipedes can be used for isolation of chitin. The chitin yield from millipede shell was also comparatively same as that of the conventional sources. The FT-IR spectrum shows that the isolate was chitin and is confirmed by comparing with standard chitin. The SEM images illustrated particular nature of chitin which can be attributed to intramolecular hydrogen bonding in chitin. This isolated chitin has vast applications in various industries. Hence, we propose that millipedes can also be used as an alternate source for large-scale extraction of chitin without depending on conventional sources.

\section{Acknowledgements}

We would like to thank the Department of Biochemistry, Kuvempu University, Shankaraghatta, Karnataka, India, for providing the laboratory facility.

Availability of data and materials

All databases are available upon request.

\section{Authors' contributions}

Dr. RHS was responsible for the experimental design, execution, and manuscript preparation. RSN was responsible for the experimental design and execution. Dr. RNA was responsible for the experimental design and preparation of manuscript. All authors read and approved the final manuscript.

Ethics approval and consent to participate

Not applicable

\section{Competing interests}

The authors declare that they have no competing interests.

\section{Publisher's Note}

Springer Nature remains neutral with regard to jurisdictional claims in published maps and institutional affiliations.

Received: 19 January 2018 Accepted: 4 June 2018

Published online: 28 June 2018

\section{References}

Abdou, E. S., Nag, K. S. A., \& Elsabee, M. Z. (2008). Extraction and characterization of chitin and chitosan from local sources. Bioresource Technology., 99, 1359-1367.

Austin, P. E., Castle, J. E., \& Albisetti, C. J. (1989). In G. Skjak-Braek, T. Anthonsen, \& P. Sandford (Eds.), Chitin and chitosan, (p. 749). Essex: Elsevier.

Blackwell J. (1969). Structure of beta-chitin or parallel chain systems of poly-beta(1-4)-N-acetyl-D-glucosamine. Biopolymers. 7(3), 281-98.

Brugnerottoa, J., Lizardib, J., Goycooleab, F. M., Argu Eelles-Monalc, W., DesbrieAresa, J., \& Rinaudo, M. (2001). An infrared investigation in relation with chitin and chitosan characterization. Polymer, 42, 3569-3580

Chassarya, P., Vincenta, T., Marcanob, J. S., Macaskiec, L. E., \& Guibala, E. (2005). Palladium and platinum recovery from bicomponent mixtures using chitosan derivatives. Hydrometallurgy, 76, 131-147.

Gardner, K. H., \& Blakwell, J. (1975). Refinement of the structure of $\beta$-chitin. Biopolymers, 14, 1581.

Herth W., Barthlott W. (1979). The site of beta-chitin fibril formation in centric diatoms. I. Pores and fibril formation. J Ultrastruct Res. 68(1), 6-15.

Minke, R., \& Blackwell, J. (1978). The structure of a-chitin. Journal of Molecular Biology, 120, 429-433.

No, H. K., \& Meyers, S. P. (1989). Crawfish Chitosan as a Coagulant in Recovery of Organic Compounds from Seafood Processing Streams. J. Agric. Food Chem. $37(3), 580-583$
Kameda T., Miyazawa M., Ono H., \& Yoshida M. (2005). Hydrogen bonding structure and stability of a-chitin studied by 13C solid-state NMR. Macromol. Biosci. 5, 103-106.

Knorr, D. (1982). Functional properties of chitin and chitosan. J. Food Sci. 47, 593-595.

Knorr, D. (1984). Use of chitinous polymers in food- A challenge for food research and development. Food Technology, 38(1), 85-97.

Rathke, T. D., \& Hodson, S. M. (1994). Review of chitin and chitosan as fiber and film formers. Journal of Macromolecular Science Reviews in Macromolecular Chemistry, C34, 375

Ravi Kumar, M. N. V. (2000). A review of chitin and chitosan applications. Reactive and Functional Polymers. 46, 1-27.

Rudall, K. M. (1963). The Chitin/Protein Complexes of Insect Cuticles, Chapter in Advances in insect physiology. 1, 257-13.

Rudall, K.M. \& Kenchington (1973), Chitin system. Biol. Rev. 48, 597-636.

Sandford, P. A. (1989). Chitosan: commercial uses and potential applications. In G. Skjak-Braek, T. Anthonsen, \& P. Sandford (Eds.), Chitin and chitosan, (pp. 51-69). London: Elsevier.

Tolaimate, A., Desbriers, J., Rhazi, M., \& Alagui, A. (2003). Contribution to the preparation of chitin and chitosan with controlled physico-chemical properties. Polymer, 44, 7939-7952.

Trang, S. T., \& Huynh, N. D. B. (2015). Physicochemical properties and antioxidant activities of chitin and chitosan prepared from pacific white shrimp waste. International Journal of Carbohydrate Chemistry, 20156 pages.

\section{Submit your manuscript to a SpringerOpen ${ }^{\circ}$ journal and benefit from:}

- Convenient online submission

- Rigorous peer review

- Open access: articles freely available online

- High visibility within the field

- Retaining the copyright to your article

Submit your next manuscript at $\boldsymbol{\nabla}$ springeropen.com 